\title{
Functional status and well being in chronic obstructive pulmonary disease with regard to clinical parameters and smoking: a descriptive and comparative study
}

\author{
Carl-Peter Engström, Lars-Olof Persson, Sven Larsson, Anna Rydén, Marianne Sullivan
}

\begin{abstract}
Background - Self-assessment questionnaires which measure the functional and affective consequences of chronic obstructive pulmonary disease (COPD) give valuable information about the effects of the disease and may serve as important tools with which to evaluate treatment.

Methods - A cross sectional comparative study was performed between patients with COPD ( $n=68$ ), stratified according to pulmonary function, and a healthy control group ( $n=89)$. A battery of well established clinical and quality of life measures (the Sickness Impact Profile (SIP), Mood Adjective Check List (MACL), and Hospital Anxiety and Depression scale (HAD)) was used to examine in which functional and affective aspects the patient group differed from the control group and how these measures related to pulmonary function and smoking habits.
\end{abstract}

Results - Compared with the controls, COPD affected functional status in most areas, not just those requiring physical activity. Forty six patients with forced expiratory volume in one second $\left(F^{2} V_{1}\right)$ below $50 \%$ predicted showed particularly high levels of dysfunction in ambulation, eating, home management, and recreation/ pastimes (SIP). Despite this, their level of psychosocial functioning and mood status was little different from that of the healthy controls. Among the patients, a subgroup reported substantial psychological distress, but mood status was only weakly, or not at all, related to pulmonary function. Smoking habits did not affect functional status or well being.

Conclusions - Quality of life is not significantly affected in patients with mild to moderate loss of pulmonary function, possibly due to coping and/or pulmonary reserve capacity. This suggests that generic self-assessment questionnaires are of limited value for detecting the early consequences of COPD. However, in later stages of the disease they are sensitive enough to discriminate between patients with different levels of pulmonary dysfunction. The low correlations between the indices of pulmonary function and the indices of affective status suggest that well being depends, to a large extent, on factors outside the clinical domain.

(Thorax 1996;51:825-830)
Keywords: chronic obstructive pulmonary disease, quality of life, Sickness Impact Profile, smoking.

Assessment of quality of life is important in providing medical care for patients with chronic diseases such as chronic obstructive pulmonary disease (COPD). Specific treatment and rehabilitation is dependent on patient-generated information such as reduced symptom burden (predominantly shortness of breath) and improved functioning, well being, and satisfaction with life.'

The most important indicator of disease severity - the forced expiratory volume in one second $\left(\mathrm{FEV}_{1}\right)$ - has shown only a weak correlation with both dyspnoea and indices of quality of life. ${ }^{2-5}$ Thus, the impact of the disease on the everyday life of patients is unlikely to be predictable from objective indicators of disease severity. Walking distance, depression, and dyspnoea have been reported to be the main determinants of impaired quality of life in COPD. Dyspnoea has also been shown to be a more prominent predictor of quality of life than physiological measurements. ${ }^{4}$ Measures of health-related quality of life are therefore used to identify problem areas experienced by the patients and to examine the outcome of rehabilitation programmes. ${ }^{6} 7$ This is facilitated by reliable and validated self-assessment measures of general and specific aspects of functional status and well being. ${ }^{8-10}$

Descriptive studies using generic quality of life questionnaires have shown conflicting results. Two studies reported most daily functions, assessed by the Sickness Impact Profile (SIP), to be profoundly affected. ${ }^{11}{ }^{12}$ However, both these studies concerned patients with advanced disease (mean $\mathrm{FEV}_{1} 0.75$ 1 and 1.021 , respectively). By contrast, two further studies which included patients with asthma and/or moderate degrees of COPD (mean $\mathrm{FEV}_{1} 64 \%$ and $70 \%$ predicted, respectively) found only modest effects on quality of life. ${ }^{13}{ }^{14}$ Another study of patients with a mean $\mathrm{FEV}_{1}$ of $34 \%$ predicted, $25 \%$ of whom were receiving domiciliary oxygen therapy, found household management, ambulation, sleep/ rest, recreation/pastimes, and work to be the major areas of disability, and financial problems and social isolation were also reported. ${ }^{15}$ However, only two studies ${ }^{11}{ }^{12}$ included proper control groups.

In one study ${ }^{12}$ smoking status was found to be related to quality of life - that is, those patients with COPD who had stopped smok- 
ing showed significantly lower scores on the SIP scale despite a worse pulmonary function.

The present study was designed to (1) describe quality of life in patients with COPD at all stages of the disease, (2) compare their quality of life with an age and sex matched healthy control group, (3) elucidate the influence of smoking habits on quality of life, and (4) relate measures of quality of life to pulmonary function $\left(\mathrm{FEV}_{1}\right)$.

\section{Methods}

DESIGN

The study was of a cross sectional design. An extensive battery of clinical and quality of life measures was used to compare functional and affective measures in a group of patients with COPD and a group of age/sex matched healthy controls. The design of the study was approved by the local ethics committee.

\section{SUBJECTS}

\section{Patient group}

Patients were recruited from the wards and outpatient clinic of the Department of Pulmonary Medicine, Göteborg, Sweden. Inclusion criteria were COPD with $\mathrm{FEV}_{1}<80 \%$ of predicted and age 40-75 years. All of the patients were smokers or former smokers with a smoking history of at least 10 pack years. Exclusion criteria were other disabling or severe diseases and/or coexistence of other causes of impaired pulmonary function. Patients with a history that indicated asthma were excluded. None of them had an acute exacerbation at the time of investigation. In order to balance for disease severity, the patients were stratified according to $\mathrm{FEV}_{1}$ with approximately equal representation of patients with an $\mathrm{FEV}_{1}$ of $<30 \%, 30-49 \%$, and $50-79 \%$ of predicted. Every tenth patient who fulfilled these criteria was invited to participate in the study and 68 accepted.

\section{Control group}

A group of 89 individuals was selected from a random sample of 500 citizens in the city of Göteborg who matched approximately the age and sex distribution of the patients. They were contacted by telephone and asked to participate in the study. Inclusion criteria were normal spirometric parameters with an $\mathrm{FEV}_{1}$ of $\geqslant 80 \%$ of predicted and no severe chronic illness. The group was stratified according to smoking history with approximately equal numbers of current smokers, former smokers, and never smokers. A summary of the sociodemographic and clinical data for the patients and controls is given in table 1 .

\section{Dropouts}

Of the patients asked to participate, 18 declined. Their mean (SD) $\mathrm{FEV}_{1}$ was 42.3 (15.0)\% of predicted. Half of them felt that they were too tired to participate and half claimed lack of time. Of the controls invited to participate in the study, 33 declined and a further 16 failed to attend.
Table 1 Sociodemographic and clinical data of the study groups as mean (SD) or frequency

\begin{tabular}{|c|c|c|}
\hline & $\begin{array}{l}\text { Patients } \\
(n=68)\end{array}$ & $\begin{array}{l}\text { Controls } \\
(n=89)\end{array}$ \\
\hline Mean (SD) age (years) & $64.6(6.8)$ & $63.0(7.6)$ \\
\hline $\operatorname{Sex}(M / F)$ & $63 / 37 \%$ & $56 / 44 \%$ \\
\hline \multicolumn{3}{|l|}{ Domestic arrangements ${ }^{1}$} \\
\hline Single & $40 \%$ & $33 \%$ \\
\hline Cohabiting & $60 \%$ & $67 \%$ \\
\hline Gainfully employed $^{2}$ & $14 / 37(38 \%)$ & $40 / 47(85 \%)$ \\
\hline \multicolumn{3}{|l|}{ Smoking status ${ }^{3}$} \\
\hline Current smokers & $46 \%$ & $34 \%$ \\
\hline Former smokers & $54 \%$ & $32 \%$ \\
\hline Never smokers & $0 \%$ & $34 \%$ \\
\hline Disease duration (years) ${ }^{4}$ & $7.6(4.7)$ & - \\
\hline \multicolumn{3}{|l|}{ Pulmonary function ${ }^{5}$} \\
\hline $\mathrm{FEV}_{1}(\%$ pred $)$ & $39.9(17.0)$ & $103.0(13.1)$ \\
\hline VC (\% pred) & $66.6(18.9)$ & $93.4(10.7)$ \\
\hline TLCO (\% pred) & $33.9(22.5)$ & - \\
\hline $\mathrm{PaO}_{2}(\mathrm{kPa})^{6}$ & $9.6(1.2)$ & - \\
\hline $\mathrm{PaCO}_{2}(\mathrm{kPa})$ & $5.7(0.9)$ & - \\
\hline Respiratory insufficiency ${ }^{7}$ & $25 \%$ & - \\
\hline
\end{tabular}

$\mathrm{FEV}_{1}=$ forced expiratory volume in one second; $\mathrm{VC}=$ vital capacity; TLCO = carbon monoxide transfer factor; $\mathrm{PaO}_{2}$, $\mathrm{PaCO}_{2}=$ oxygen and carbon dioxide tensions.

${ }^{1}$ Single was defined as living alone, divorced or

widow/widower. Cohabiting was defined as married or living together with a partner.

${ }^{2}$ At least half time and if age was below 65 which is the retirement age in Sweden.

${ }^{3}$ Smoking was defined as at least 10 pack years.

${ }^{4}$ Self-reported duration since the first occurrence of troublesome symptoms.

${ }^{5}$ Spirometric values reported here are without bronchodilatation in the control group and after bronchodilatation in the patient group.

${ }^{6}$ Arterial blood gases were only measured in those 46 patients with $\mathrm{FEV}_{1}$ below $50 \%$ predicted.

${ }^{7}$ Patients who needed oxygen therapy.

\section{MEASURES}

Physiological measures

Routine spirometric tests were performed with a Vitalograph spirometer before and $15 \mathrm{~min}$ utes after inhalation of $1 \mathrm{mg}$ terbutaline. Carbon monoxide transfer factor (TLCO) was measured by the single breath method. Normal values were those described by Berglund ${ }^{16}$ and Salorinne, ${ }^{17}$ respectively. Arterial blood gas tensions $\left(\mathrm{PaO}_{2}\right.$ and $\left.\mathrm{PaCO}_{2}\right)$ were measured in patients with an $\mathrm{FEV}_{1}$ of $<50 \%$ predicted.

\section{Psychological measures}

Functional status was measured with the Swedish version of the Sickness Impact Profile (SIP). ${ }^{18}$ This is a generic self-assessment questionnaire designed to facilitate comparisons between different health conditions over a range of important functional aspects. ${ }^{19}$ It consists of 136 items grouped into 12 specific functional categories: ambulation (A), body care/movement (BCM), mobility (M), emotional behaviour (EB), social interaction (SI), alertness behaviour (AB), communication (C), work (W), sleep/rest (SR), eating (E), home management (HM), and recreation/pastimes (RP). A predetermined weighting system from the original SIP was used to quantify degree of dysfunction. The scale scores are expressed as a percentage of maximum dysfunction to form a scale of $0-100$. A score of 0 on each subscale indicates no dysfunction at all, a score above 0 but no higher than 10 indicates slight to moderate dysfunction, and scores above 10 indicate marked dysfunction. ${ }^{20}$ The scores of the categories $\mathrm{A}, \mathrm{BCM}$, and $\mathrm{M}$ are also aggregated to form a physical dimension (Phd). Categories $\mathrm{EB}, \mathrm{SI}, \mathrm{AB}$, and $\mathrm{C}$ form a psychosocial dimen- 
sion (Psd), and all 12 categories are included in an overall SIP score (Oall SIP).

Emotional status was measured by two selfassessment scales - the Swedish version of the Hospital Anxiety and Depression scale $(\mathrm{HAD})^{21}{ }^{22}$ and a Swedish Mood Adjective Check List (MACL). ${ }^{23}$ The HAD scale ${ }^{24}$ has been specifically developed for the detection of anxiety and depression in patients with somatic conditions. It consists of 14 items and gives separate scores for anxiety and depression. Scores below 8 indicate no clinical distress, scores from 8 to 10 indicate possible psychiatric morbidity, and scores above 10 probable pathological levels of distress. The MACL consists in its full version of 71 mood adjectives measuring six bipolar mood dimensions. In the present study a shorter 38 item version was used, covering the basic dimensions of $\operatorname{mood}^{21}$ - that is, pleasantness/unpleasantness, activity/inactivity, and calmness/tension. Scale scores range from 1.0 to 4.0 , with a higher score indicating a more positive emotional state. The scores of these dimensions may in turn be aggregated into an overall MACL score which has been shown to be a good indicator of general well being. ${ }^{21}$

The two measures of emotional state supplement each other. The HAD scale provides specific information about the frequency of pathological distress because of its validated cut-off limits. The MACL, on the other hand, concerns overall well being and various aspects of mood. Thus, it is a more sensitive tool of the general levels of affective status for comparisons between groups.

\section{PROCEDURES}

All subjects completed the psychological questionnaires in a prepared waiting room at a visit to the outpatient clinic. The subjects were instructed by a research nurse who was available for assistance if requested. At the same time demographic and other background data were collected. Immediately afterwards the physiological examination was performed by a physician and/or a trained nurse. A small fee was paid to the control subjects for their

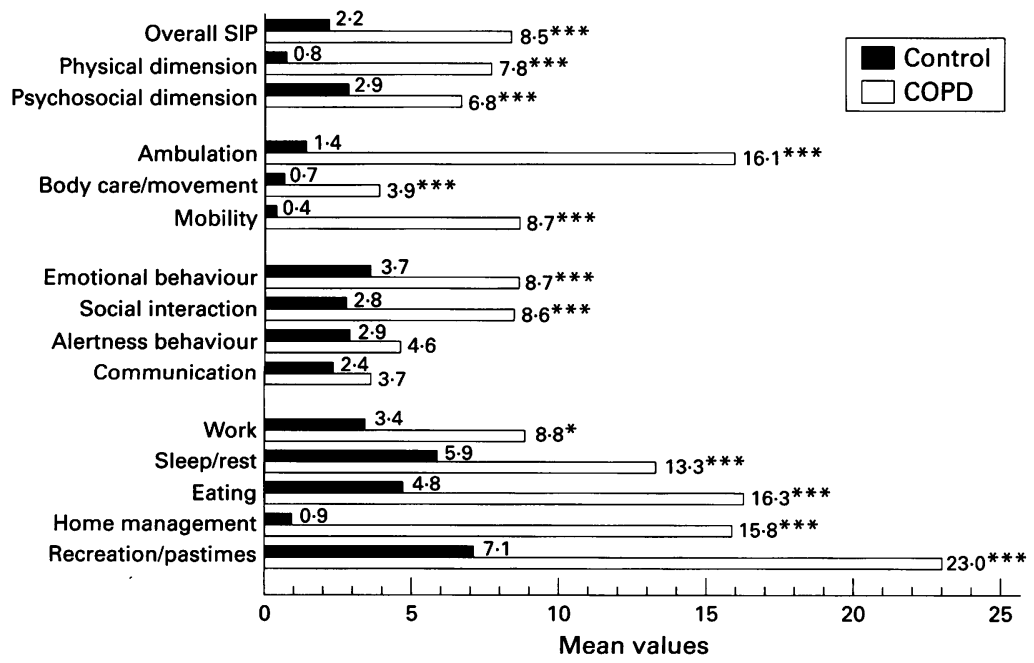

Figure 1 Mean Sickness Impact Profile (SIP) scores for patients with COPD and healthy controls. $* p<0.05 ; * * p<0.01 ; * * * p<0.001$ (Mann-Whitney $U$ test). participation. Full confidentiality was guaranteed and the identification register was destroyed after the investigation was completed.

STATISTICAL ANALYSES

Descriptive statistics were computed for each of the variables analysed. Non-parametric statistics $^{25}$ were used in all analyses. The Mann-Whitney U test was performed when two groups were compared, and the KruskalWallis $\mathrm{H}$ test when three or more groups were compared in the same analysis (nonparametric ANOVA). Fisher's exact probability test was used in comparisons between proportions and Spearman's rank correlation to examine relations between variables. Differences were considered statistically significant if $p<0.05$. The statistical software package used was SPSS for Windows, version 6.0.

\section{Results}

SOCIODEMOGRAPHIC AND CLINICAL

CHARACTERISTICS

Among the patients, 21 (31\%) had an $\mathrm{FEV}_{1}$ of $<30 \%$ predicted and $46(68 \%)$ had a value of $<50 \%$ (table 1 ). The remaining 22 patients $(32 \%)$ had values between $50 \%$ and $80 \%$. Seventeen patients $(25 \%)$ had a $\mathrm{PaO}_{2}$ of $<8$ $\mathrm{kPa}$ continuously or intermittently. Only 14 of the 37 patients below 65 years of age were gainfully employed compared with 40 of 47 for the control group. The patient group also showed a slightly higher frequency of single living.

SMOKING

All of the subjects in the patient group were current smokers or former smokers and $46 \%$ continued to smoke despite their disease (table $1)$. The ex-smokers among the controls had smoked considerably less (20.6 (14.3) pack years) than the ex-smokers among the patients (36.9 (17.6) pack years) and than the current smokers among the controls (31.9 (14.8) pack years) and the patients (37.7 (14.6) pack years).

FUNCTIONAL STATUS (SIP)

Large differences were found for most categories of the SIP scale between patients and controls (fig 1), all of which reached statistical significance except for alertness behaviour and communication ( $p<0.05$, Mann-Whitney $U$ test). The difference was largest for all physical functions involving ambulation. The psychosocial impact of COPD affected both emotional behaviour and social interaction. There was a profound impact of the disease on home management and recreation/pastimes as well as on the basic functions of eating and sleep/rest.

Of the control group $80 \%$ did not experience any physical dysfunction at all that is, the SIP score was zero (fig 2). The corresponding proportion for the patient group was only $22 \%$. In the patient group $31 \%$ had an SIP score of $>10$ compared with $2 \%$ of the controls. These differences between groups 
were highly significant $(\mathrm{p}<0.05$, Fisher's exact probability test). Although significant ( $p$ $<0.01$ ), the corresponding differences in the psychosocial dimension and overall SIP scores were less marked.

Patients with the most advanced disease $\left(\mathrm{FEV}_{1}<50 \%\right.$ of predicted) reported the worst dysfunction in everyday life (fig 3). They differed significantly ( $p<0.01$, MannWhitney $U$ test) from the control group in all SIP categories and dimensions except for alertness behaviour (AB). This group also differed significantly $(p<0.05)$ from the patients with $\mathrm{FEV}_{1}$ of $50-79 \%$ of predicted in the categories HM, M, A, RP, E, and SI, as well as on the Phd and Oall dimensions. The differences were particularly strong for the first four categories $(p<0.0001)$. No significant differences between any of the groups were found for the psychological category alertness behaviour. Patients with $\mathrm{FEV}_{1}$ of $50-79 \%$ of predicted differed considerably less from the controls (fig 3), although significant differences were found for the three categories A, M, and $\mathrm{EB}$, as well as for the Phd dimension ( $\mathrm{p}$ $<0.05)$.

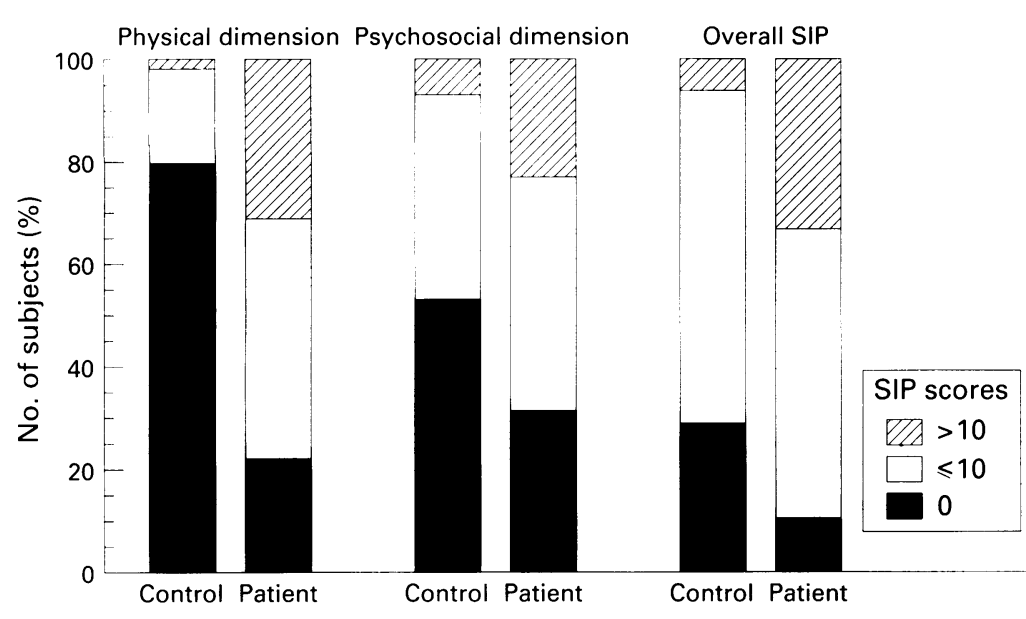

Figure 2 Proportion of subjects with no dysfunction (SIP score $=0$ ), slight dysfunction (SIP score $\leqslant 10$ ) or marked dysfunction (SIP score $>10)$ over the aggregated SIP dimensions in the two study groups.

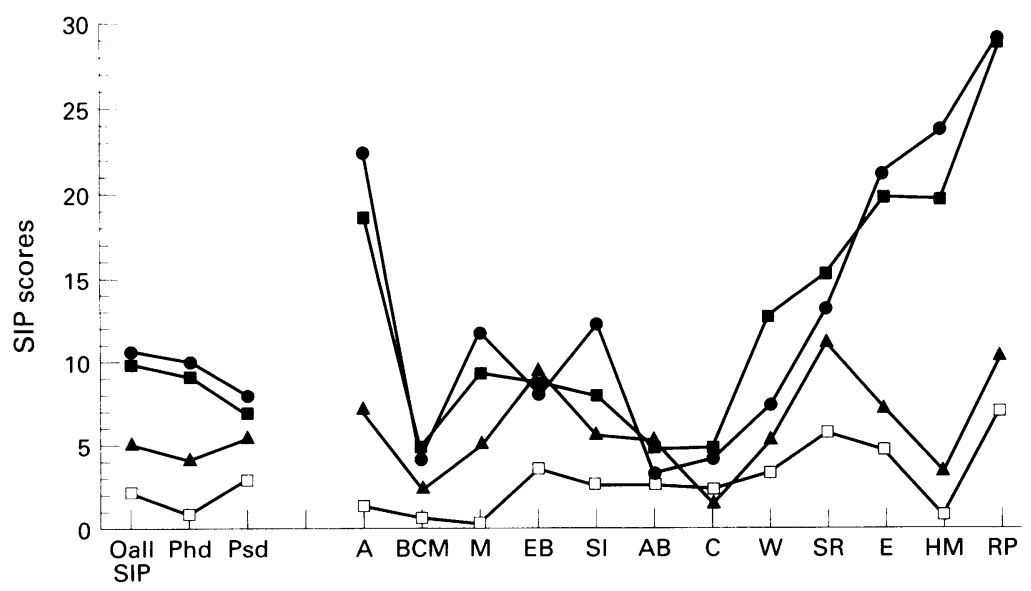

Figure 3 Mean SIP scores in the three stratified patient groups: $0=F E V_{1}<30 \%$ predicted $(n=21) ; \mathbf{\square}=F E V_{1} 30-49 \%$ predicted $(n=25) ; \boldsymbol{\Lambda}=F E V_{1} 50-79 \%$ predicted $(n=22)$ and the control group $(\square, n=89)$. Oall SIP = total SIP score; Phd $=$ physical dimension $P s d=$ psychosocial dimension $A=$ ambulation; $B C M=$ body care/movement; $M=$ mobility; $E B=$ emotional behaviour; $S I=$ social interaction; $A B=$ alertness behaviour; $C=$ communication; $W=$ work; $S R=$ sleep/rest $E=$ eating; $H M=$ home management,$R P=$ recreation/pastimes.

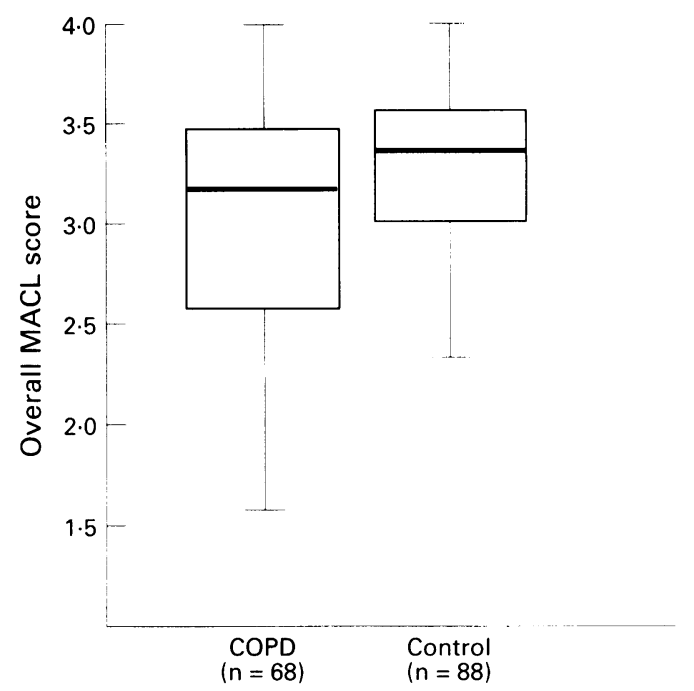

Figure 4 Box plots of the aggregated Mood Adjective Check List (MACL) scores showing medians, quartiles, and minimum and maximum values. $p<0.05$ (Mann-Whitney $U$ test).

EMOTIONAL STATUS

No statistically significant differences were found between the groups for either depression or anxiety measured by the HAD scale (MannWhitney $U$ test). However, the variation in scores was somewhat larger for patients than controls. Although most patients had normal values, a few scored far beyond the cut-off level. In the patient group pathological levels (scores above 10$)$ were seen in $13 \%(n=9)$ on the anxiety scale and $7 \%(\mathrm{n}=5)$ on the depression scale. The corresponding proportions for the control group were $6 \%(n=5)$ and $1 \%(n=1)$, respectively. These differences between the patients and the controls were not significant (Fisher's exact probability test). No significant correlations were found between $\mathrm{HAD}$ scores and percentage predicted $\mathrm{FEV}_{1}$ (Spearman's rank correlation). In contrast, relatively strong and significant correlations were found with the SIP scores. The correlations between anxiety and depression scores with overall SIP scores were 0.46 and 0.57 , respectively.

Box plots for emotional well being (aggregated mood scores) are presented in fig 4 . The median values for patients and controls were 3.37 and 3.19 , respectively, a difference that corresponds to about $6 \%$ of the scale range. Although small, this difference reached significance. The variation in scores was considerably higher in the patient group than in the control group, indicating a subgroup with profound psychological distress. No significant correlation was found between the mood score and percentage predicted $\mathrm{FEV}_{1}$.

EFFECTS OF SMOKING ON QUALITY OF LIFE

Smoking status was categorised in the control group as smokers, former smokers, and never smokers, and in the patient group as smokers and former smokers (none of the patients had never smoked). No significant differences were found between smoking status and SIP scores, mood dimensions, and HAD scores in either the patient or the control group (Kruskal- 
Wallis $\mathrm{H}$ test). Likewise, no significant correlations were found between pack years and SIP dimensions (Spearman's rank correlation).

\section{Discussion}

This study covers essential aspects of healthrelated quality of life in well defined study groups of patients and healthy controls. Thus, it adds further information to previous studies.

The results show that COPD affects functional status in most areas, particularly those daily functions that regularly need physical activity - ambulation, mobility, and home management - but also recreation/pastimes, eating, sleep/rest, and aspects of psychosocial functioning. However, it was primarily the patients with an $\mathrm{FEV}_{1}$ of $<50 \%$ predicted who showed high levels of dysfunction. This is in line with previous studies in which considerable effects on quality of life have been demonstrated in severe disease but not in the early stages. ${ }^{11-15}$

It is clear that impaired pulmonary function leads to difficulties other than with performing physical activities. Noteworthy were the effects on recreation/pastimes, eating, sleep/rest, and aspects of psychosocial functioning, indicating that at low levels of pulmonary function almost every aspect of functional status is affected. The high levels of dysfunction in these latter areas call for intervention not addressed by traditional physical training programmes in rehabilitation. The inclusion of "leisure education" may be of particular interest to patients with COPD because many are either too old (above the retirement age) or too afflicted by their disease to be gainfully employed. A programme of leisure education and therapeutic recreation that has been developed and proved beneficial in the USA ${ }^{26}$ has been modified for Swedish conditions ${ }^{27}$ and may be applied to patients with COPD.

Other problem areas familiar to clinicians were also emphasised by our quality of life results - for example, problems with eating and sleep/rest. Eating problems, together with high resting energy expenditure, may in turn lead to malnutrition which has been reported to be a serious problem in the late stages of COPD and is an established risk factor for mortality in COPD. ${ }^{28}$ Thus, a dietician may improve the eating habits and nutritional status among patients. Disturbance of sleep may also have considerable adverse effects on quality of life and merits thorough investigation. In a study of quality of life and mechanical ventilation in restrictive pulmonary disorders, sleep quality was one of the strongest predictors of global quality of life. ${ }^{29}$

The HAD scale has proved to be a valid selfassessment measure of anxiety and depression in patients with cancer and other somatic diseases. ${ }^{30-32}$ Although no significant correlations were found between the HAD scores and pulmonary function $\left(\mathrm{FEV}_{1} \%\right.$ predicted) in the present study, they related significantly in the expected directions with the other indices of quality of life (SIP and MACL). This indicates the relevance of including the HAD scales as specific measures of psychiatric morbidity in
COPD. However, pathological levels of anxiety and depression were found in only a relatively small subgroup of patients.

Despite the affected functional status, the level of well being (MACL) in our patients differed only slightly from that of the healthy controls. The affective measures were weakly or not at all related to pulmonary function $\left(\mathrm{FEV}_{1}\right)$. Such results might seem surprising but are not unique for COPD. Similar findings have been reported in other chronic conditions. ${ }^{2122} 3334$ These results suggest that emotional well being tends to be more closely related to factors other than those traditionally measured in clinical studies. Recent research suggests that "coping mechanisms" may have an important effect on the sense of well being in chronic diseases. ${ }^{35}$

No difference in quality of life was seen between healthy smokers, never smokers, or former smokers. Smoking as such does not seem to influence quality of life. The differences seen in quality of life between cases and controls in the present study must therefore be explained by disease processes rather than differences in smoking habits. In a previous study ${ }^{12}$ Prigatano et al found better quality of life in former smokers than in current smokers in spite of the fact that the current smokers had better pulmonary function and were younger. However, that study differed from ours in that the patients had more advanced disease and all had respiratory insufficiency. Such differences in patient selection probably explain the conflicting data. Moreover, the results from our control group contradict the conclusion that the difference is dependent on smoking status per se.

The finding that patients with $\mathrm{FEV}_{1}$ below $50 \%$ predicted reported most dysfunctions suggests a potential for successful adaptation above this level. COPD progresses slowly over many years. Most patients tend, more or less unconsciously, to limit their physical activity gradually in accordance with the slowly increasing impairment of pulmonary function. However, when the pulmonary function is severely impaired, even basic activities of daily living are affected. It is much more difficult to cope when eating and sleep/rest are affected.

This study has shown that well established self-assessment instruments that measure the various aspects of health-related quality of life can contribute considerably to a more diversified understanding of the patients' situation. Clinical descriptions of patients with COPD are commonly restricted to their disease-specific symptoms, pulmonary function tests, and arterial blood gas tensions, and rarely include details of the consequences for their everyday life. The information yielded by a comprehensive questionnaire such as the SIP may serve as an important aid to rehabilitation in identifying patientspecific problems, individualising rehabilitation programmes, and evaluating treatment. This is particularly true for patients with $\mathrm{FEV}_{1}$ values below $50 \%$ predicted.

This study was supported by grants from the Swedish Counci for Social Research and the Swedish Council for Planning and 
Coordination of Research. We gratefully acknowledge the assistance of Mrs Ann-Marie Hilmersson, clinical research nurse, in monitoring the study.

1 Jones PW. Measurement of health-related quality of life in asthma and chronic obstructive airways disease. In: Walker SR, Rosser MR, eds. Quality of life assessment. London: Kluwer Academic Publishers, 1993:301-20.

2 Mahler DA, Harver A. A factor analysis of dyspnea ratings, respiratory muscle strength, and lung function in patients with chronic obstructive pulmonary disease. Am Rev with chronic obstructive put
Respir Dis 1992;145:467-70.

3 Wegner RE, Jörres RA, Kirsten DK, Magnussen H. Factor analysis of exercise capacity, dyspnoea ratings and lung
and function in patients with severe COPD. Eur Respir F 1994; 7:725-9.

4 Mahler DA, Faryniarz K, Tomlinson D, Colice GL, Robins AG, Olmstead EM, et al. Impact of dyspnea and physiologic function on general health status in patients with chronic obstructive pulmonary disease. Chest 1992; 102:395-401

5 Jones PW, Baveystock CM, Littlejohns P. Relationships between general health measured with the Sickness Impact Profile and respiratory symptoms, physiological measures and mood in patients with chronic airflow limitation. $\mathrm{Am}$ and mood in patients with chronic

6 Fishman AP. Pulmonary rehabilitation research. Am Rev Respir Crit Care Med 1994;149:825-33.

7 Curtis JR, Deyo RA, Hudson LD. Health-related quality of life among patients with chronic obstructive pulmonary disease. Thorax 1994;49:162-70.

8 Ware JE. Standards for validating health measures:definition and content. F Chron Dis 1987;40:473-80.

9 Anderson RT, Aaronson NK, Wilkin D. Critical review of the international assessments of health-related quality of life. Quality of Life Research 1993;2:369-95.

10 Patrick DL, Ericksson P. Assessing health-related quality of life for clinical decision-making. In: Walker SR, Rosser $\mathrm{MR}$, eds. Quality of life assessment. London:Kluwer MR, eds. Quality of life assessm

11 McSweeney AJ, Grant I, Heaton RK, Adams KM, Timms RM. Life quality of patients with chronic obstructive pulmonary disease. Arch Intern Med 1982;142:473-8.

2 Prigatano GP, Wright EC, Levin D. Quality of life and its predictors in patients with mild hypoxemia and chronic obstructive pulmonary disease. Arch Intern Med 1984 144:1613-9.

13 Kaptein AA, Brand PLP, Dekker FW, Kerstjens HAM Postma DS, Sluiter HJ. Quality of life in a long-term multicentre trial in chronic nonspecific lung disease: assessment at baseline. Eur Respir f 1993;6:1479-84.

14 Schrier AC, Dekker FW, Kaptein AA, Dijkman JH. Quality of life in elderly patients with chronic nonspecific lung disof life in elderly patients with chronic nonspecil

15 Williams SJ, Bury MR. Impairment, disability and handicap in chronic respiratory illness. Soc Sci Med 1989;29:609-16. 6 Berglund E, Birath G, Bjure J, et al. Spirometric studies in normal subjects. I. Forced expirograms in subjects between 7 to 70 years of age. Acta Med Scand 1963;173:185-91.
17 Salorinne Y. Single-breath pulmonary diffusing capacity. Reference values and application in connective tissue diseases and in various lung diseases. Scand $\mathcal{f}$ Respir Dis 1976; Suppl 96

18 Sullivan M, Ahlmén M, Archenholtz B, Svensson G. Measuring health in rheumatoid disorders by means of a Swedish version of the Sickness Impact Profile: results from a population study. Scand F Rheum 1986;15:193-200.

19 Bergner M, Bobbit RA, Carter WB, Gilson BS. The Sickness Impact Profile: development and final revision of a health status measure. Med Care 1981;19:787-805.

20 Sullivan $M$. The Sickness Impact Profile (SIP): an instrument for overall health assessment, a basic evaluation. 7 Drug Ther Res 1988;13:167-9.

21 Lundquist C, Siösteen A, Blomstrand C, Lind B, Sullivan M. Spinal cord injuries. Clinical, functional and emotional status. Spine 1991;16:78-83.

22 Sullivan M, Karlsson J, Sjöström L, Backman L, Bengtsson C, Bouchard C,et al. Swedish obese subjects (SOS) - an intervention study of obesity. Baseline evaluation of health intervention study of obesity. Baseline evaluation of health and psychological functioning in the

23 Sjöberg L, Svensson E, Persson LO. The measurement of mood. Scand f Psychol 1979;20:1-18.

24 Zigmond AS, Snaith RP. The Hospital Anxiety and Depression Scale. Acta Psychiatr Scand 1983;67:361-70.

25 Siegel S. Nonparametric statistics for the behavioural sciences. New York:McGraw-Hill, 1956.

26 O Morrow G, Reynolds R. Therapeutic recreation. A helping profession. Englewood Cliffs, New Jersey:Prentice Hall, 1989 .

27 Norling I, Schleien S, Bender M. Fritid och rekreation för utvecklingsstörda. Solna:Riksförbundet FUB, 1992.

28 Wilson DO, Rogers RM, Wright EC, Anthonisen NR. Body weight in chronic obstructive pulmonary disease. Am Rev Respir Dis 1989;139:1435-8.

29 Pehrsson K, Olofson J, Larsson S, Sullivan M. Quality of life of patients treated by home mechanical ventilation due to restrictive ventilatory disorders. Respir Med 1994;88:21-6.

30 Bergman B, Sullivan M, Sörenson S. Quality of life during chemotherapy for small cell lung cancer. An evaluation with generic health measures. Acta Oncol 1991;30:947-57.

31 Hopwood P, Howell A, Maguire P. Screening for psychiatric morbidity in patients with advanced breast cancer: valida-
tion of two self-report questionnaires. $B r f$ Cancer tion of two self.

32 Aylard PR, Gooding JH, Mckenna PJ, Snaith RP. A validation study of three anxiety and depression self-assessment scales. $\mathcal{F}$ Psychosom Res 1987;31:261-8.

33 Ahlmén M, Bengtsson C, Sullivan M, Bjelle A. A comparison of overall health between patients with rheumatoid arthritis and a population with and without rheumatoid arthritis. Scand $\mathcal{F}$ Rheumatol 1990, 19:413-21.

34 Sullivan M, Ahlmén M, Bjelle A. Health status assessment in rheumatoid arthritis. 1 . Further work on the validity of in rheumatoid arthritis. 1. Further work on the validity of
the Sickness Impact Profile. $\mathcal{F}$ Rheumatol 1990;17:439-47.

35 Lazarus RS. Coping theory and research: past, present, and future. Psychosom Med 1993;55:234-47. 